\title{
Effect of Various Inhibitors on Lipase Action of Thermophilic Fungus Humicola lanuginosa S-38
}

\author{
Wen-Hsiung Liu,* Teruhiko Beppu and Kei Arima \\ Department of Agricultural Chemistry, The University of Tokyo, Bunkyo-ku, Tokyo
}

Received April 18, 1973

\begin{abstract}
The hydrolysis of olive oil by the Humicola lipase was inhibited by the addition of $n$ alcohols, fatty acids and surface active agents. The inhibition of $n$-alcohols was overcomed by the addition of more substrate but not by the addition of more enzyme. The inhibition of fatty acids and bile salts was eliminated by adding calcium ion. It was concluded that the inhibition of the Humicola lipase by $n$-alcohols, fatty acids and bile salts was not due to inactivation of the enzyme directly but due to the displacing of the substrate from the oil/water interface, thus blocking the enzyme from the substrate.
\end{abstract}

It has been established ${ }^{2,3)}$ that pancreatic lipase has the unusual property of being functional only at an oil/water interface and that the hydrolysis reaction is dependent upon the interfacial area rather than the bulk concentration of the substrate. Since the complete hydrolysis of a triglyceride by lipase into glycerol and three fatty acid moieties is a three-step reaction, it is apparent that the condition of the oil/water interface changes continuously during the whole hydrolysis process. At the same time, any substances which can alter the nature of the oil/water interface can markedly influence the hydrolysis of triglyceride. It was reported ${ }^{4)}$ that such a reagent affecting the reaction condition could not be classified as a true enzyme effector because a true enzyme effector must combine with the enzyme and must affect the function of the enzyme.

In order to maintain the maximum rate of hydrolysis of triglyceride by lipase, many attempts have been made using agitation and metals and surface active agents, such as bile salts and synthetic surfactants, to provide an

$\uparrow$ Studies on the Lipase of Thermophilic Fungus Humicola lanuginosa. Part V. For Part IV see Reference 1).

* Present address: Laboratory of Fermentation, Department of Agricultural Chemistry, National Taiwan University, Taipei, Taiwan, Republic of China. adequate interfacial area of the substrate. However, it was reported ${ }^{4}$ that the effect of surface active agents on the lipase reaction was complex and dependent on the chemical nature of the agents used. On the other hand, the physical conditions of the substrate necessary for lipase activity, such as emulsification of the substrate, substrate with constant shaking or substrate with adding cofactors, were also different for lipases from various sources. ${ }^{5 \sim 11}$

In the previous paper, ${ }^{12}$ it was reported that Humicola lipase was purified and confirmed to be homogeneous by disc electrophoresis and ultracentrifugal analyses. In the present study, effects of various inhibitors on the action of the Humicola lipase were investigated by using this purified preparation.

\section{MATERIALS AND METHODS}

Reaction conditions. The reaction mixture consisted of $1 \mathrm{ml}$ of olive oil, $2 \mathrm{ml}$ of $0.05 \mathrm{M}$ Tris- $\mathrm{HCl}$ buffer ( $\mathrm{pH} 8.0$ ), $1 \mathrm{ml}$ of reagent or water and $1 \mathrm{ml}$ of lipase solution. This mixture was incubated in test tubes under constant shaking at $45^{\circ} \mathrm{C}$ for $2 \mathrm{hr}$. Enzyme reaction was terminated with the addition of $20 \mathrm{ml}$ of acetone-ethanol mixture $(1: 1, \mathrm{v} / \mathrm{v})$. The lipase activity was estimated as described previously. ${ }^{131}$

Chemicals. Olive oil, $n$-alcohols, $n$-hydrocarbons, sodium salts of fatty acid, bile salts and other chemicals 
with a reagent grade were obtained from the Tokyo Kasei, Kogyo Co., Ltd. or the Kokusan Chemical Work, Ltd. Synthetic surfactants were obtained from the Kao Soap Co., Ltd.

\section{RESULTS}

Effect of n-alcohols and n-hydrocarbons on the lipase action

The effects of $n$-alcohols and $n$-hydrocarbons on the lipase action as a function of their chain length are presented in Fig. 1. Lipase action was inhibited by the addition of $n$ -

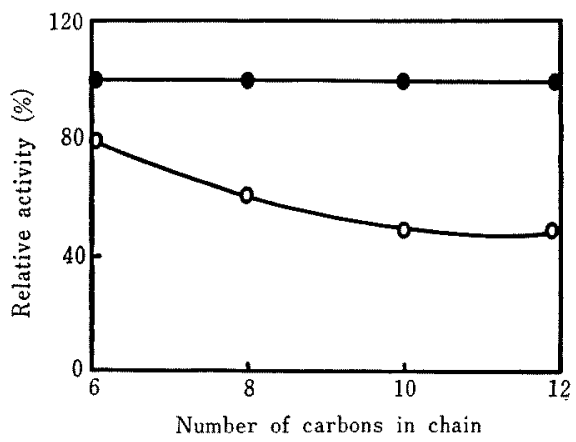

FIG. 1. Effect of $n$-Alcohols and $n$-Hydrocarbons of Various Carbon Chains on the Lipase Action.

O, $n$-alcohols

, $n$-hydrocarbons.

The mixtures which contained $1 \mathrm{ml}$ of olive oil and $0.1 \mathrm{ml}$ of effector solution ( $n$-alcohols or $n$-hydrocarbons or $\mathrm{H}_{2} \mathrm{O}$ for the control) were adjusted to $4 \mathrm{ml}$ by adding $0.05 \mathrm{M}$ Tris- $\mathrm{HCl}$ buffer ( $\mathrm{pH} \mathrm{8.0)}$ ) and then shaken at $45^{\circ} \mathrm{C}$ for $10 \mathrm{~min}$ before adding $1 \mathrm{ml}$ of lipase solution. Reaction was conducted under constant shaking at $45^{\circ} \mathrm{C}$ for $2 \mathrm{hr}$.

alcohols. The inhibition ratio increased as their chain length increased. On the contrary, $n$-hydrocarbons showed no effect on lipase action regardless of their chain length.

As shown in Fig. 2, the inhibition of lipase action was promoted by increasing the amount of $n$-decanol whereas $n$-decane showed no effect on lipase action. The inhibition of lipase action by the addition of $n$-decanol could gradually be overcomed by increasing the amount of substrate (Fig. 3), but it was not changed by the concentration of the enzyme (Fig. 4).

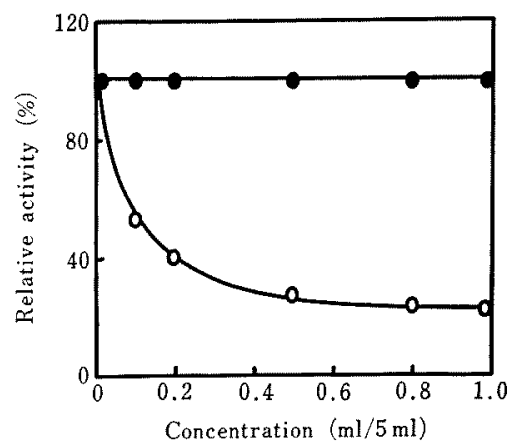

Fig. 2. Effect of Concentrations of $n$-Decanol and $n$-Decane on the Lipase Action.

O, $n$-decane; $\boldsymbol{0}$, -decanol.

The reaction mixtures contained $1 \mathrm{ml}$ of olive oil, $1 \mathrm{ml}$ of lipase solution, $n$-decanol or $n$-decane of various amounts $(0 \sim 1 \mathrm{ml})$ and were adjusted to $5 \mathrm{ml}$ by adding $0.05 \mathrm{M}$ Tris-HCl buffer ( $\mathrm{pH} 8.0$ ). Reaction conditions were the same as those described in Fig. 1.

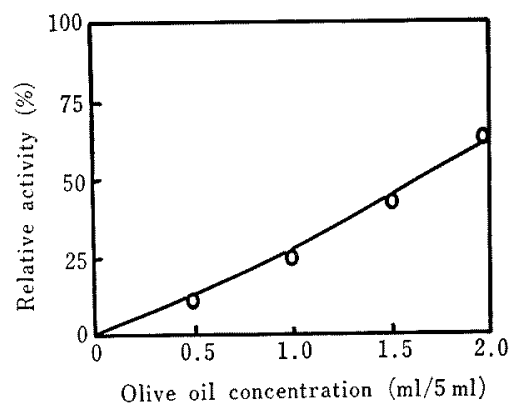

Fig. 3. Effect of Substrate Concentration on the Lipase Action in the Presence of $n$-Decanol.

The reaction mixtures contained $1 \mathrm{ml}$ of lipase solution, $0.8 \mathrm{ml}$ of $n$-decanol, olive oil of various amounts $(0.5 \sim 1 \mathrm{ml})$ and were adjusted to $5 \mathrm{ml}$ by adding $0.05 \mathrm{M}$ Tris- $\mathrm{HCl}$ buffer ( $\mathrm{pH} 8.0$ ). The reaction mixture of the control contained $1 \mathrm{ml}$ of lipase solution, $1 \mathrm{ml}$ of olive oil and $3 \mathrm{ml}$ of $0.05 \mathrm{M}$ Tris-HCl buffer ( $\mathrm{pH} 8.0$ ). Reaction conditions were the same as those described in Fig. 1.

Effect of synthetic surfactants on the lipase action

The effects of various synthetic surfactants on lipase action are presented in Fig. 5. Lipase action was strongly inhibited by the addition of anionic surfactants, such as sodium polyoxyethylene alkyl sulfonate and sodium dodecylbenzene sulfonate. On the other hand, nonionic surfactants, such as polyoxyethylene 


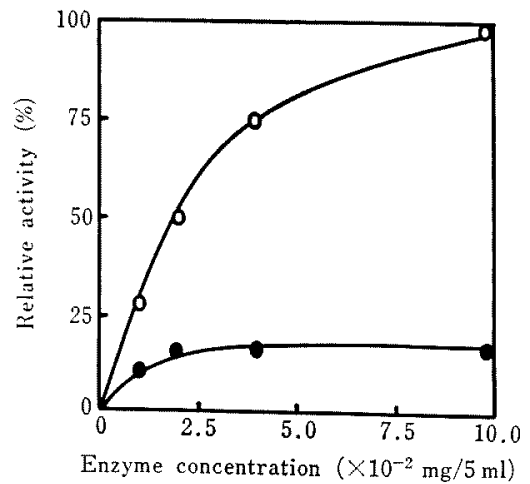

FIG. 4. Effect of Enzyme Concentration on the Hydrolysis of Olive Oil.

The reaction mixtures contained $1 \mathrm{ml}$ of olive oil, $1 \mathrm{ml}$ of lipase solution of various concentrations, $0.8 \mathrm{ml}$ of $n$-decanol $(\mathbf{O})$ or $\mathrm{H}_{2} \mathrm{O}(\mathrm{O})$ and were adjusted to $5 \mathrm{ml}$ by adding $0.05 \mathrm{M}$ Tris- $\mathrm{HCl}$ buffer ( $\mathrm{pH} 8.0$ ). Reaction conditions were the same as those described in Fig. 1.

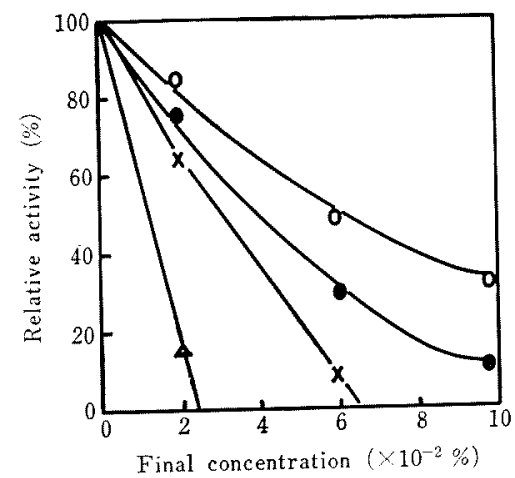

FIG. 5. Effect of Various Synthetic Surfactants on the Lipase Action.

O, Polyoxyethylene octylphenol ether; 9 , Polyoxyethylene lauryl ether; $x$, Sodium polyoxyethylene alkyl sulfonate; $\triangle$, Sodium dodecylbenzene sulfonate.

octylphenol ether and polyoxyethylene lauryl ether, showed less inhibitory effect on the lipase action than anionic surfactants. It was apparent that the effect of synthetic surfactants on the lipase action depended upon the chemical nature of the agents used.

Effects of fatty acids and bile salts on the lipase action

The effects of fatty acids on lipase action are shown in Fig. 6. Lipase action was inhibited by the addition of fatty acids and

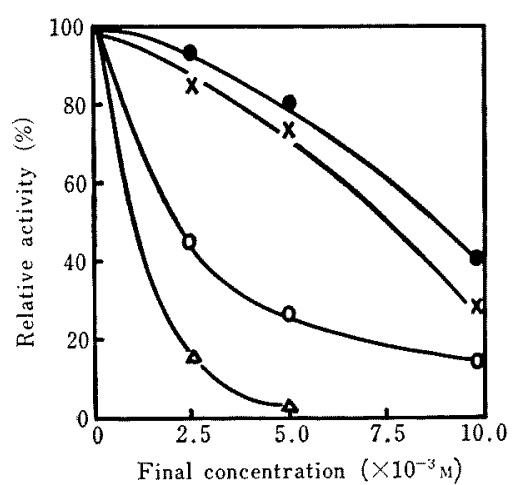

FIG, 6. Effect of Various Fatty Acids on the Lipase Action.

-, Lauric acid; $\curlywedge$, Stearic acid; $\bigcirc$, Oleic acid; $\triangle$, Linoleic acid.

the inhibition rate increased as the amount of fatty acids increased. The lipase action was markedly inhibited by adding a low concentration of long-chain unsaturated fatty acids, such as oleic acid and linoleic acid, but the inhibition by saturated fatty acids, such as lauric acid and stearic acid, required a higher concentration.

In order to observe the effect of bile salts on the lipase action, three kinds of bile salts, sodium cholate, sodium deoxycholate and sodium taurocholate, were examined. As shown in Fig. 7, it was found that all of these

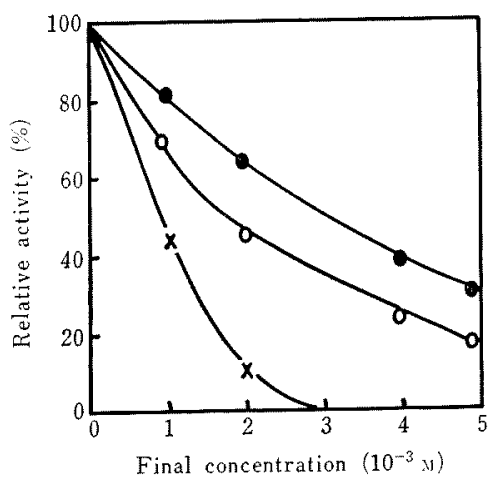

Fig. 7. Effect of Various Bile Salts on the Lipase Action.

- Sodium cholate; 0 , Sodium deoxycholate; $\wedge$, Sodium taurocholate.

bile salts showed an inhibitory effect on lipase action. 
Effects of metal ions on the lipase action

The effects of various metal ions on lipase action were examined and the results are presented in Table I. Experiments adding various metal ions in the reaction system showed that the lipase action was stimulated by $\mathrm{Ca}^{2+}$ and $\mathrm{Mg}^{2+}$, whereas inhibited by $\mathrm{Hg}^{2+}$ and $\mathrm{Cu}^{2+} \mathrm{Na}^{+}$and $\mathrm{K}^{+}$ions were without effect. When the enzyme was pre-incubated with various metal ions at $25^{\circ} \mathrm{C}$ for $1 \mathrm{hr}$ and then dialyzed against distilled water for $24 \mathrm{hr}$, the activation or inhibition of lipase action by the added metal ions could not be observed. It indicated that the effect of these metal ions was not due to irreversible binding with the enzyme.

Table I. Effect of Various Metal Ions on THE LIPASE ACTION

\begin{tabular}{lcc}
\hline \multirow{2}{*}{$\begin{array}{c}\text { Metal ion } \\
\left(1 \times 10^{-2} \mathrm{M}\right)\end{array}$} & \multicolumn{2}{c}{ Relative activity $(\%)$} \\
\cline { 2 - 3 } & Before dialysis $^{a)}$ & After dialysis \\
& & \\
\hline None & 100.0 & 100.0 \\
$\mathrm{Na}^{+}$ & 100.0 & 100.0 \\
$\mathrm{~K}^{+}$ & 100.0 & 100.0 \\
$\mathrm{Ca}^{2+}$ & 120.0 & 100.0 \\
$\mathrm{Mg}^{2+}$ & 115.0 & 95.0 \\
$\mathrm{Hg}^{2+}$ & 45.0 & 90.0 \\
$\mathrm{Cu}^{2+}$ & 75.0 & 95.0 \\
\hline
\end{tabular}

a) Determined as described in the text.

b) The mixtures which consisted of $2 \mathrm{ml}$ of $2 \times 10^{-2}$ $\mathrm{M}$ of various metal chlorides solutions and $2 \mathrm{ml}$ of lipase solution $(0.1 \mathrm{mg})$ were incubated at $25^{\circ} \mathrm{C}$ for $1 \mathrm{hr}$. Using collodion bags the mixtures were dialyzed against distilled water at $5^{\circ} \mathrm{C}$ for $24 \mathrm{hr}$, and the residual activities were determined.

As shown in Fig. 8, the lipase action was affected by the addition of $\mathrm{Ca}^{2+}$ of various concentrations. The maximum rate of lipase reaction was obtained when $5 \times 10^{-3} \mathrm{M} \mathrm{Ca}^{2+}$ was added. On the other hand, the inhibitory effects of sodium oleate and sodium taurocholate were reduced by adding $\mathrm{Ca}^{2+}$ The inhibition effect of $3.2 \times 10^{-3} \mathrm{M}$ sodium oleate was eliminated by the addition of $5 \times 10^{-3} \mathrm{M}$ $\mathrm{Ca}^{2+}$, while the inhibitions effect of $1.8 \times 10^{-3} \mathrm{M}$ sodium taurocholate was only reduced to $20 \%$ inhibition by adding $1 \times 10^{-1} \mathrm{M} \mathrm{Ca}^{2+}$.

To observe the effect of the delayed addition of $\mathrm{Ca}^{2+}$ on oleate inhibition, calcium ion was added to the reaction system $1 \mathrm{hr}$ after the addition of oleate. It was found that the oleate inhibition was immediately eliminated by the addition of $\mathrm{Ca}^{2+}$ and that lipase action retum to normal (Fig. 9).

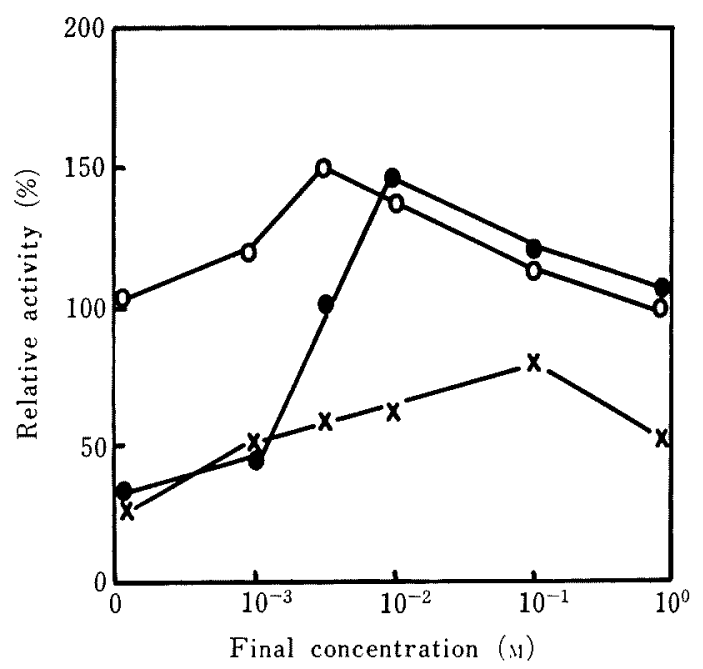

Fig. 8. Effect of Calcium Ion Concentration on the Lipase Action.

0 , Calcium alone; $\bullet$, Calcium $+3.2 \times 10^{-3} \mathrm{M}$ sodium oleate; $\sim$, Calcium $+1.8 \times 10^{-3} \mathrm{M}$ sodium taurocholate.

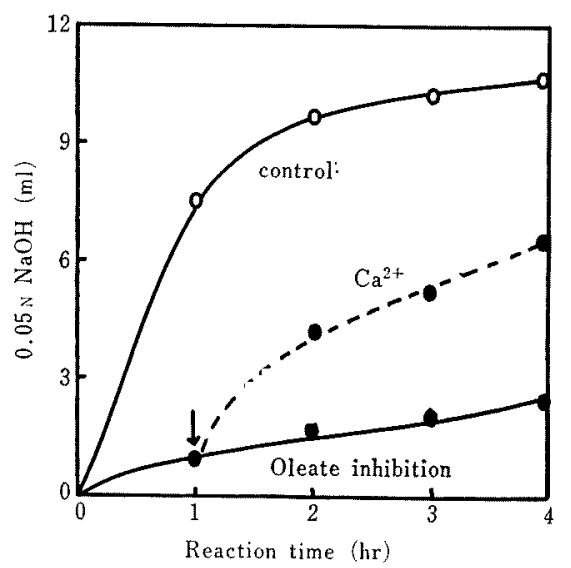

FIG. 9. Effect of the Delayed Addition of $\mathrm{Ca}^{2+}$ on the Oleate Inhibition of the Humicola Lipase.

The oleate inhibition was performed by adding $1 \times 10^{-2} \mathrm{M}$ sodium oleate to the control system at time zero. The arrow shows when the metal ion was added to the oleate inhibition system. The concentration of metal ion was $1 \times 10^{-1} \mathrm{M}$. 


\section{DISCUSSION}

Since the lipase reaction occurs only at an oil/water interface, the rate of hydrolysis of triglyceride by lipase is not only concerned with the interfacial area of the substrate but also with the amount of enzyme adsorbed at the interface. Therefore, any substance which does not directly affect the enzyme but alters the nature of the oil/water interface can show a marked influence on the hydrolysis of triglyceride.

As shown in Fig. 1, the hydrolysis of olive oil by the Humicola lipase was inhibited by the addition of $n$-alcohols. It has been postulated $^{7}$ that the orientation of a triglyceride molecule at an oil/water interface is such that the glycerol moiety of the triglyceride is laid on the surface of the fat droplet and that the hydrocarbon chains extended toward the center of the droplet. Therefore, it is reasonable to assume that in an oil/water heterogeneous system, the hydroxy portion of the $n$-alcohol is laid on the surface of oil phase and that the hydrocarbon portion is inserted in the oil phase. Thus, the ester linkages of triglyceride which are laid on the surface of oil phase are displaced from the interface by the hydroxy group of $n$-alcohol. Consequently, the interfacial area of the substrate which provides for the lipase reaction is limited by the addition of $n$-alcohol. Since the rate of lipase hydrolysis is dependent upon the interfacial area rather than the bulk concentration of the substrate, it is comprehensible that the inhibition by $n$-alcohol could be eliminated by the addition of more substrate which increases the interfacial area, but not by the addition of more enzyme (Fig. 3 and Fig. 4). It was suggested that Humicola lipase was not inactivated by the addition of $n$-alcohol and that the inhibition was due to a decrease in the interfacial area of the substrate. These results are coincidental with the inhibiting effect of $n$-alcohol on the hydrolysis of methyloleate by pancreatic lipase. ${ }^{14)}$

Many investigators have reported that lipase action was stimulated by the addition of calcium ion. ${ }^{4,8,15,16)}$ It was generally thought that the primary role of calcium ion was to remove fatty acids formed in the hydrolysis as insoluble calcium soaps, and thus, change the interfacial substrate-water relationship to a favorable one for enzyme action. However, in the case of Pseudomonas and Geotrichum lipases, ${ }^{17}$ the inhibition of these lipases by fatty acid could not be reversed by the delayed addition of calcium ion. The inhibition of these lipases by fatty acid was obviously due to inactivating the enzyme directly.

As shown in Fig. 9, the hydrolysis of olive oil by the Humicola lipase was inhibited by the addition of oleate at time zero. However, the oleate inhibition was immediately eliminated by the addition of calcium ion after the inhibition treatment was carried out for $1 \mathrm{hr}$. The added calcium ions probably combined with the oleate as insoluble soaps which changed the state of the oil/water interface to one favorable for enzyme action. It is also concluded that the inhibition of Humicola lipase by oleate during the hydrolysis of olive oil was not due to inactivation of the enzyme directly. The oleate inhibition was due to a decreasing rate of hydrolysis by displacement of the substrate from the interface as in the case of $n$-alcohol, thus blocking the enzyme from the substrate.

Acknowledgement. Authors are deeply grateful to Drs. Makari Yamasaki, Takeshi Uozumi and Takashi Saiki, Department of Agricultural Chemistry, the University of Tokyo, for many valuable discussions.

\section{REFERENCES}

1) W. H. Liu, T. Beppu and K. Arima, Agr. Biol. Chem., 37, 1349 (1973).

2) P. Desnuelle, Advan. in Enzymol., 23, 129 (1961).

3) G. Benzonana and P. Desnuelle, Biochim. Biophys. Acta, 105, 121 (1965).

4) E. D. Wills, Advan. in Lipid Res., 3, 197 (1965).

5) B. Borgstrom, Biochim. Biophys. Acta, 13, 149 (1954).

6) W. P. Schoor and P. Melius, ibid., 212, 173 (1970).

7) F. H. Matton and R. A. Volpenhein, J. Amer. Chem. Soc., 43, 286 (1966).

8) M. Iwai, Y. Tsujisaka and J. Fukumoto, J. Gen. 
Appl. Microbiol., 10, 87 (1964).

9) J. Fukumoto, M. Iwai and Y. Tsujisaka, ibid., 10, 257 (1964).

10) Y. Ota and K. Yamada, Agr. Biol. Chem., 30, 351 (1966).

11) Y. Ota and K. Yamada, ibid., 30, 1030 (1966).

12) W. H. Liu, T. Beppu and K. Arima, Agr. Biol. Chem., 37, 157 (1973).

13) K. Arima, W. H. Liu and T. Beppu, ibid., 36,
1913 (1972).

14) F. H. Mattson, R. A. Volpenhein and L. Benjamin, J. Biol. Chem., 245, 5335 (1970).

15) F. Schonheyder and K. Volqvartz, Physiol. Scand. Acta, 10, 62 (1945).

16) R. C. Lawrence, Dairy Sci, Abstr., 29, 59 (1967).

17) J. L. Smith and J. A. Alford, Appl. Microbiol., 14, 699 (1966). 